CINAHPA | 2017 - Congresso Internacional de Ambientes Hipermídia para Aprendizagem.

\title{
EXPERIÊNCIA NO DESENVOLVIMENTO DE PROJETO DE PRODUTO DE MODA PARA O PÚBLICO INFANTIL SOB A ÓTICA DO DESIGN UNIVERSAL:
}

PROJETO INTERDISCIPLINAR

EXPERIENCE IN DEVELOPING A FASHION PRODUCT DESIGN FOR CHILDREN UNDER THE PERSPECTIVE OF UNIVERSAL DESIGN: INTERDISCIPLINARY PROJECT

Jenifer Oliveira Mariano, Graduação ${ }^{1}$

Luana Macedo da Silva, Graduação ${ }^{2}$

Silvia Maria Corrêa, Graduação ${ }^{3}$

Maria Antônia Romão, M. Sc ${ }^{4}$

Verena Ferreira Tidei de Lima, M. Sc

1. Universidade Estadual de Londrina

e-mail: jeni.oliver21@gmail.com

2. Universidade Estadual de Londrina

e-mail: luanadesignerdemoda@gmail.com

3. Universidade Estadual de Londrina e-mail: silvinhax2@gmail.com

4. Universidade Estadual de Londrina e-mail: maria.antonia.romao@gmail.com

5. Universidade de São Paulo e-mail:verenalima@gmail.com 
$16^{\circ}$ Ergodesign - Congresso Internacional de Ergonomia e Usabilidade de Interfaces Humano Tecnológica: Produto, Informações Ambientes Construídos e Transporte

$16^{\circ}$ USIHC - Congresso Internacional de Ergonomia e Usabilidade de Interfaces Humano Computador CINAHPA

CINAHPA | 2017 - Congresso Internacional de Ambientes Hipermídia para Aprendizagem.

\section{Palavras-chave (Projeto de produto, Design Universal, Ergonomia)}

Este estudo apresenta os conhecimentos e resultados envolvidos em um projeto de produtos vestíveis para o público infantil de 4 a 8 anos sob a lente do Design Universal ao longo da experiência projetual vivenciada na $2^{\mathrm{a}}$ série do Curso em Design de Moda de uma Instituição Pública do Paraná. Constatou-se que, para o desenvolvimento adequado do projeto de produto de moda, se faz necessária a imersão no universo do público, de maneira a identificar os aspectos ergonômicos a serem considerados, como: mobilidade, desenvolvimento motor, diferença corporal, aprendizagem e linguagem lúdica do público infantil; demandando, assim, o uso de mecanismos para a adaptação de tamanho, aviamentos de fácil manuseio e desenvolvimento de tabela de medidas diferenciada. O projeto buscou preservar a linguagem lúdica e trabalhar a interatividade da criança com o ambiente que o cerca por meio da superfície têxtil, composição formal e outros objetos complementares aos produtos de vestuário projetados.

\section{Keywords (Product design, Universal Design, Ergonomics)}

This study presents the knowledge and results involved in a project of clothing products for children aged 4 to 8 years old under the perspective of Universal Design throughout the design process experienced during the 2nd grade of an undergraduate Course in Fashion Design of a Public Institution of Paraná. It was verified that for an accurate development of a fashion design product, it is necessary a deep engagement with the public, in order to identify the ergonomics aspects to be considered, such as: mobility, motor skills development, physical particularities, learning, and playful language of children. These mentioned aspects require, then, the use of mechanisms for size fitting, easy-to-handle trims, and the development of a measurement adapted table. The project sought to maintain the playful language and to handle the interaction of children with their surrounding environment through textile surface, shape composition, and other additional objects related to designed clothing products.

\section{Introdução}

O ensino de métodos e bases que norteiam a formação do raciocínio projetual se faz presente nas diferentes escolas de design (SANCHES; BARBOSA; ORTUÑO; MARTINS, 2016). Para Lawson (2011), o raciocínio projetual está estritamente ligado ao processo cognitivo, marcado por movimentos contínuos de avanços e retrocessos, envolto por etapas não estáticas que devem ser retroalimentadas. Para tanto, o ensino de Design deve contemplar uma abordagem flexível e integrada (BOMFIM, 1997; LAWSON, 2011; SANCHES, 2010; SANCHES et al, 2016).

Diante do exposto, o presente estudo refere-se ao desenvolvimento de projeto de produto do vestuário realizado na $2^{\mathrm{a}}$ série do Curso de bacharelado em Design de Moda de uma
Instituição Pública do Paraná, ao longo de uma atividade acadêmica interdisciplinar, envolvendo as disciplinas de: Metodologia de Projeto, Ergodesign, Modelagem Computadorizada, Laboratório da Forma, Processos Têxteis, Tecnologia da Confecção e Desenho de Moda. A proposta interdisciplinar teve como objetivo o desenvolvimento de uma coleção de produtos de vestuário constituída por 10 composições destinadas ao público infantil de 4 a 8 anos, sendo que ao menos duas das composições deveriam ser orientadas a públicos geralmente não atendidos em virtude de diversas deficiências e/ou necessidades educacionais especiais - e projetadas sob a ótica do Design Universal ${ }^{1}$ em uma

1 De acordo com o manual "Desenho universal: habitação de interesse social", publicado pelas Secretarias Estaduais de Habitação e dos Direitos da Pessoa com Deficiência, do Estado de São Paulo, a expressão Desenho Universal foi usada pela primeira vez pelo arquiteto Ron Mace, em 1985, nos Estados 


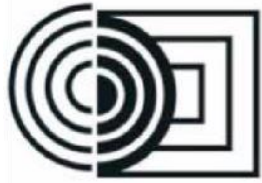

$16^{\circ}$ Ergodesign - Congresso Internacional de Ergonomia e Usabilidade de Interfaces Humano Tecnológica: Produto, Informações Ambientes Construídos e Transporte

$16^{\circ}$ USIHC - Congresso Internacional de Ergonomia e Usabilidade de Interfaces Humano Computador

CINAHPA | 2017 - Congresso Internacional de Ambientes Hipermídia para Aprendizagem. perspectiva de inclusão.

Desse modo, estabeleceu-se que a oportunidade de design teria como objetivo suprir as necessidades e especificidades do público infantil masculino e feminino da faixa etária previamente determinada, contemplando, também, crianças com síndrome de down, uma vez que o projeto fora desenvolvido sob a ótica do design universal.

\section{Método}

A presente pesquisa é de natureza aplicada, com abordagem qualitativa e de caráter exploratório. Para o desenvolvimento de um projeto de produto do vestuário se faz necessário, para maior aprofundamento, realizar a pesquisa exploratória, que segundo Severino (2016), busca informações do objeto em questão, delimitando o campo de trabalho e fazendo com que as condições das manifestações estejam mapeadas de acordo com o objeto pesquisado.

Tendo como ponto de partida uma pesquisa bibliográfica, inicialmente foi aplicado um questionário semiestruturado aos pais, referente ao público infantil como um todo, disponibilizado online na plataforma Googledrive nos $06 \mathrm{de}$ outubro a 21 de outubro de 2016.

Concomitante, e considerando o objetivo da proposta interdisciplinar de desenvolver ao menos duas composições orientadas a um público

Unidos. Inicialmente cunhado no campo do desenvolvimento de projetos urbanos e arquitetura, o termo expandiu-se para além do universo do design. A proposta do design universal é que os objetos desenvolvidos sob essa perspectiva, quaisquer que sejam, atendam às necessidades e especificidades das pessoas, quaisquer que sejam suas singularidades. No que diz respeito à proposta interdisciplinar elucidada no presente trabalho, A questão do design universal foi inserida no sentido de ampliar a esfera de ação do design para além de públicos convencionais usualmente atendidos, de maneira a incluir públicos cujas singularidades são comumente desconsideradas. com deficiência e/ou necessidades educacionais especiais, foi executada uma segunda pesquisa de campo por meio de um questionário semiestruturado, aplicado aos pais e educadores de uma instituição especializada em desenvolver trabalhos referentes às Necessidades Educacionais Especiais. A intenção desse segundo questionário foi a de mapear possíveis públicos cujas singularidades não fossem usualmente contempladas pelo desenvolvimento de produtos convencionais.

Foi observado que, além dos questionários realizados, seria necessária uma aproximação direta com o público para aprofundar os conhecimentos relacionados ao cotidiano deste no intuito de identificar suas necessidades e aspectos emocionais. Desse modo, ocorreu o primeiro contato com o mesmo por meio de observação no espaço escolar, em uma escola convencional. $\mathrm{Na}$ sequência, foi realizada uma entrevista semiestruturada registrada em vídeo, contando com a participação de 7 crianças de 4 a 8 anos, com a devida autorização dos responsáveis. Os dados foram processados por intermédio de análise qualitativa.

\section{Necessidades e especificidades do público alvo}

Segundo Morace (2012), o Lively Kids, crianças de 4 a 8 anos, possuem o próprio mundo de fábulas, no qual é alimentada a paixão pela natureza, pelo mundo animal e vegetal. Ainda de acordo com o autor, os pais possuem o papel fundamental no desenvolvimento e na formação da identidade da criança, muitas vezes como canal responsável por filtrar os aspectos de consumo, o que influencia diretamente no desenvolvimento do produto destinado ao público infantil. O caráter do produto deve ser orientado pela sensibilidade infantil, pelo desenvolvimento de códigos e pela linguagem criativa (MORACE, 2012).

Os dados coletados apontam que as crianças nessa faixa etária são ativas; a maioria já está em contato com escolas ou creches; mesmo 


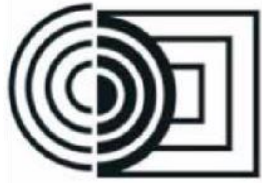

$16^{\circ}$ Ergodesign - Congresso Internacional de Ergonomia e Usabilidade de Interfaces Humano Tecnológica: Produto, Informações Ambientes Construídos e Transporte

$16^{\circ}$ USIHC - Congresso Internacional de Ergonomia e Usabilidade de Interfaces Humano Computador

CINAHPA | 2017 - Congresso Internacional de Ambientes Hipermídia para Aprendizagem. com a pouca idade já opinam sobre o que gostam e o que usam, deixando claro quando não gostam de determinado produto; e certos elementos os atraem, como cores, personagens, texturas, brilhos e até mesmo estampas com predominância de letras do alfabeto. Dentre os pontos negativos apontados, destacaram-se: desgaste das peças em certas regiões do corpo da criança; valor elevado da peça em relação a sua qualidade e tempo de uso; problemas de usabilidade (aviamentos/adaptações); carência de estampas diferenciadas para o público infantil feminino; escassez de ajustes de tamanho, acarretando a perda rápida da roupa, além de etiquetas com materiais que provocam incômodo em contato com a pele.

Ambas as pesquisas resultaram na delimitação das crianças com síndrome de down como o público a ser contemplado pelo projeto à luz do design universal.

A definição do público permitiu um aprofundamento a respeito das necessidades e suas implicações. Grave (2010 apud HESS;

PACHECO, 2015) expõe que as roupas, de certa forma, oportunizam aos usuários estabelecer uma identificação com o seu meio e encontrar roupas que sirvam bem ao tipo físico, proporcionandolhes sentimentos de inclusão e participação.

Nesse contexto, as crianças com síndrome de down, para além do desenvolvimento cognitivo especial, segundo Cunningham (2008 apud HESS, PACHECO, 2015), apresentam ainda algumas especificidades corporais que devem ser consideradas ao longo do projeto de produto do vestuário: baixa estatura; tronco de menor altura e de maior circunferência abdominal; e dificuldades em relação à coordenação motora fina. Ainda, Cunningham (2008 apud HESS, PACHECO, 2015) afirma que as pessoas com síndrome de down não seguem a curva usual de crescimento, de maneira que as diferenças corporais necessitam ser consideradas.

Segundo Pereira (2011), para que haja a interação da criança com a roupa, é crucial apropriar-se dos conhecimentos do design, pois este auxilia na sua construção. De acordo com Gonçalves (p. 41, 2017), “o vestuário pedagógico dispõe a vestimenta infantil como um instrumento de ensino. Sendo essa uma tendência do mercado da moda, tem como destaque a interação da peça com a criança, possibilitando a aprendizagem e aquisição do conhecimento, através da interação do ato de vestir". Segundo Brougere (2006), a experiência lúdica, por si só, é um processo culturalmente rico, exercendo influência sobre diversos outros processos sociais, como a escolarização de crianças com necessidades educacionais especiais.

Isto posto, o projeto contemplou o desenvolvimento de soluções que contribuam com a aprendizagem por meio da interação da criança com o produto de moda.

\section{$4 \quad$ O projeto}

Ao buscar as soluções, o projeto pautou-se rigorosamente nas necessidades e especificidades do público.

Por intermédio da linguagem lúdica, o projeto buscou proporcionar à criança momentos de diversão a partir do ato de se vestir, transformando-o também em um momento de aprendizagem. Com foco na interatividade, a proposta vai além do simples vestir, visando contribuir com o desenvolvimento motor e cognitivo do público, a partir de elementos e mecanismos que incentivem e promovam o contato entre as crianças e o mundo externo. Assim, os produtos desenvolvidos foram projetados para estimular o público infantil nos momentos lúdicos de recreação.

\section{$5 \quad$ Aspectos ergonômicos}

Iida (1990) "elucida que os produtos devem conter algumas características básicas para que eles interagem de forma positiva com os seus utilizadores. Dentre elas estão a qualidade técnica, ergonômica e estética. A qualidade técnica refere- 


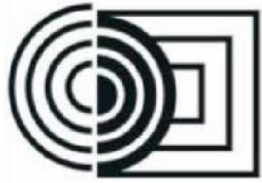

se à parte funcional do produto e a eficácia com que ele realiza sua função; já a qualidade ergonômica do produto está relacionada à facilidade de manuseio, à inclusão de questões antropométricas, ao fornecimento claro de informações, bem como aspectos que envolvem o conforto e a segurança. A qualidade estética possui a função de tornar os produtos visualmente agradáveis através da combinação de formas, cores, materiais e texturas".

Segundo Martins (2008), as ações relacionadas ao vestir o corpo devem ser contempladas no projeto de produto de vestuário, objetivando solucionar e identificar com antecedência danos à saúde, desconforto, ocorrência de acidentes e dificuldades de manejo, por meio do estudo de aspectos anatômicos, antropométricos e biomecânicos. Ainda de acordo com o autor, o projeto do vestuário não pode ignorar os aspectos estéticos, requisitos técnicos, necessidades, limitações e mobilidade relacionadas à faixa etária.

A pesquisa permitiu identificar as necessidades do público, bem como as inadequações apontadas por este no que diz respeito aos produtos já existentes. As informações foram convertidas em parâmetros projetuais, apontados na tabela a seguir (tabela 1). É importante destacar que, ainda que os parâmetros de projeto estejam elencados e segmentados na tabela em relação aos parâmetros ergonômicos e de usabilidade, esses não são necessariamente separáveis.

\begin{tabular}{|l|l|}
\hline $\begin{array}{l}\text { Parâmetros } \\
\text { ergonômicos e de } \\
\text { usabilidade }\end{array}$ & Parâmetros de projeto \\
\hline $\begin{array}{l}\text { Facilidade de } \\
\text { manejo; }\end{array}$ & $\begin{array}{l}\text { - Aviamentos adequados em termos de } \\
\text { tamanho e simples em termos de } \\
\text { acionamento; }\end{array}$ \\
\hline $\begin{array}{l}\text { Facilidade de } \\
\text { assimilação; } \\
\text { Compatibilidade } \\
\text { com o usuário; } \\
\text { Entendimento do } \\
\text { usuário. }\end{array}$ & $\begin{array}{l}\text { - Design de superfície para estimular a } \\
\text { criança e auxiliar no desenvolvimento } \\
\text { cognitivo e motor; }\end{array}$ \\
\hline $\begin{array}{l}\text { Facilidade de } \\
\text { manutençãano; agregados para estimular a a }\end{array}$ & $\begin{array}{l}\text { criançiliar no desenvolvimento } \\
\text { cognitivo e motor; } \\
\text { - Linguagem lúdica. }\end{array}$ \\
\hline
\end{tabular}

$16^{\circ}$ Ergodesign - Congresso Internacional de Ergonomia e Usabilidade de Interfaces Humano Tecnológica: Produto, Informações Ambientes Construídos e Transporte

$16^{\circ}$ USIHC - Congresso Internacional de Ergonomia e Usabilidade de Interfaces Humano Computador

CINAHPA | 2017 - Congresso Internacional de Ambientes Hipermídia para Aprendizagem.

\begin{tabular}{|l|l|}
\hline & - Adaptação da tabela de medidas para \\
& facilitar a mobilidade, uma vez que o \\
& público em questão encontra-se em \\
& constante movimentação, e contemplar \\
& variações corporais; \\
& - Ajustes relacionados ao tamanho das \\
Seģas para proporcionar uma extensão & da vida útil e contemplar variações \\
& corporais; \\
& - Utilização de aviamentos que não \\
& ofereçam risco em termos de material e \\
& de tamanho; \\
& - Utilização de etiquetas que não sejam \\
incômodas.
\end{tabular}

Tabela 1: Parâmetros de Projeto

Fonte: Própria a partir de Jordan (1998) e Martins (2008).

Se fez essencial, ainda, um estudo mediante as normas da ABNT (2015) a respeito da segurança do vestuário infantil.

No que concerne à adaptação da tabela de medidas infantil, foram conferidas folgas positivas no sentido da largura (tabela 2). As alterações foram aplicadas em grande parte da coleção, com a cautela para que a construção formal do produto de vestuário não fosse prejudicada. 


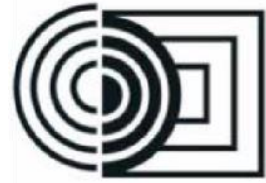

\begin{tabular}{|l|l|l|l|}
\hline Medidas & 4 & 6 & 8 \\
\hline Altura da Cabeça & 23 & 24,5 & 25 \\
\hline Altura do Gancho & 19 & 20 & 21 \\
\hline Altura do Joelho & 32 & 36 & 40 \\
\hline Altura do Quadril & 9 & 11 & 13 \\
\hline Cintura* & 58 & 60 & 62 \\
\hline Colarinho & 27,5 & 28,9 & 30,3 \\
\hline Comprimento Braço & 35 & 40 & 44 \\
\hline Comprimento Calça & 63 & 72 & 79 \\
\hline Comprimento Cotovelo & 19 & 21 & 22 \\
\hline Comprimento da Cintura & 23,8 & 26,2 & 28,6 \\
\hline Comprimento Saia & 24,5 & 32 & 39,5 \\
\hline Comprimento Vestido & 48 & 58 & 68 \\
\hline Contorno Cabeça & 53 & 54 & 55 \\
\hline Costas* & 31 & 32 & 34 \\
\hline Entrepernas & 44 & 52 & 58 \\
\hline Circunferência do Braço & 19 & 20 & 22 \\
\hline Circunferência do Joelho & 26 & 27 & 28 \\
\hline Ombro & 12,8 & 9,4 & 10 \\
\hline Punho com Folga & 68 & 72 & 76 \\
\hline Quadril* & 62 & 66 & 70 \\
\hline Tórax* & & 13,5 \\
\hline Folgas postivas apticas & & \\
\hline
\end{tabular}

* Folgas positivas aplicadas na largura.

Tabela 2: Tabela de medidas adaptadas

Fonte: Elaboração própria a partir de adaptação de SENAI (2007).

Os parâmetros projetuais anteriormente mencionados foram viabilizados e convertidos em soluções de projeto por meio de experimentações a partir de mockups, relacionadas essencialmente à matéria prima, aviamentos, modelagens e mecanismos específicos. As soluções encontram-se na tabela abaixo (tabela 3).

\begin{tabular}{|l|l|}
\hline Parâmetros de projeto & Soluções de projeto \\
\hline - Aviamentos adequados em & - Elásticos, botões de pressão \\
termos de manuseio e simples em & plásticos, zíperes plásticos \\
termos de acionamento. & em locais de fácil acesso. \\
\hline
\end{tabular}

$16^{\circ}$ Ergodesign - Congresso Internacional de Ergonomia e Usabilidade de Interfaces Humano Tecnológica: Produto, Informações Ambientes Construídos e Transporte

$16^{\circ}$ USIHC - Congresso Internacional de Ergonomia e Usabilidade de Interfaces Humano Computador

CINAHPA | 2017 - Congresso Internacional de Ambientes Hipermídia para Aprendizagem.
- Design de superfície para estimular a criança e auxiliá-la no desenvolvimento cognitivo e motor;

- Itens agregados para estimular a criança e auxiliá-la no

desenvolvimento cognitivo e motor;

- Linguagem lúdica;

- Manejo intuitivo dos

mecanismos de vestir e desvestir. desgaste.

- Adaptação da tabela de medidas para facilitar a mobilidade, uma vez que o público em questão encontra-se em constante movimentação, e contemplar variações corporais;

- Ajustes relacionados ao tamanho das peças para proporcionar uma extensão da vida útil e contemplar variações corporais;

- Utilização de aviamentos que não ofereçam risco em termos de material e de tamanho;

- Utilização de etiquetas que não sejam incômodas.

Tabela 3: Soluções de projeto

Fonte: Própria

A delimitação das matérias-primas utilizadas também considerou aspectos como conforto térmico, alta resiliência, fácil manutenção e conforto.

\section{$6 \quad$ Resultados}

Os produtos projetados buscam contribuir com o desenvolvimento da criança por meio da linguagem lúdica e da superfície têxtil. Tendo como referência o mundo animal, os produtos tentam promover a imaginação da criança, sua interação junto ao meio externo que a cerca, e contribuir ainda com o desenvolvimento de sua motricidade fina, a partir da manipulação do produto vestível e suas extensões.
Estamparia, bordado, agradáveis sensações táteis (poliamida, poliéster com enteado, algodão fio 30

- Uso de cores como exemplo: uso de cores distintas das demais, em unidas ao fechar o botão);

Bonecos que acompanham maneira, permitindo que a criança se vista a semelhança boneco.

nádegas a partir da aplicação de superfícies têxteis positiva;

Elásticos, botões de pressão de tamanho;

Botões de pressão

Etiquetas estampadas internamente. equivalentes entre si, e
Realização:

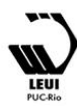




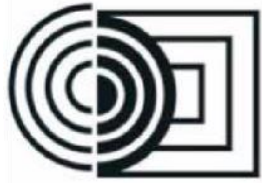

ERGODESIGN USIHC CINAHPA $16^{\circ}$ Ergodesign - Congresso Internacional de Ergonomia e Usabilidade de Interfaces Humano Tecnológica: Produto, Informações Ambientes Construídos e Transporte

$16^{\circ}$ USIHC - Congresso Internacional de Ergonomia e Usabilidade de Interfaces Humano Computador

CINAHPA | 2017 - Congresso Internacional de Ambientes Hipermídia para Aprendizagem. confeccionadas.

Abaixo encontram-se as duas composições

\begin{tabular}{|c|c|}
\hline $\begin{array}{l}\text { Macacão } \\
\text { "peixinho" } \\
\text { colorido" } \\
\text { (Figura 1) }\end{array}$ & $\begin{array}{l}\text { - Bordado em formato de olho; } \\
\text { - Estampa (costas) de escamas; } \\
\text { - Decote em alusão ao formato de uma boca; } \\
\text { - Aplicação de "escamas" coloridas de tecido duplo } \\
\text { com tingimento no verso; } \\
\text { - Uso de botōes de pressão e cores equivalentes na } \\
\text { entreperna, promovendo a assimilação do encaixe. }\end{array}$ \\
\hline $\begin{array}{l}\text { Composição } \\
\text { "tartaruga, } \\
\text { ligeirinha" } \\
\text { (Figura 2) }\end{array}$ & $\begin{array}{l}\text { - Camiseta básica com estampa figurativa de } \\
\text { tartaruga localizada embaixo do bolso; } \\
\text { - Colete de tela com aplicação de módulos em forma } \\
\text { de hexágonos, em alusão ao casco da tartaruga; } \\
\text { - Shorts sem costura lateral, com estampa corrida, } \\
\text { uso de elástico no cós e aplicação de patinhas com } \\
\text { enchimento na barra. }\end{array}$ \\
\hline
\end{tabular}

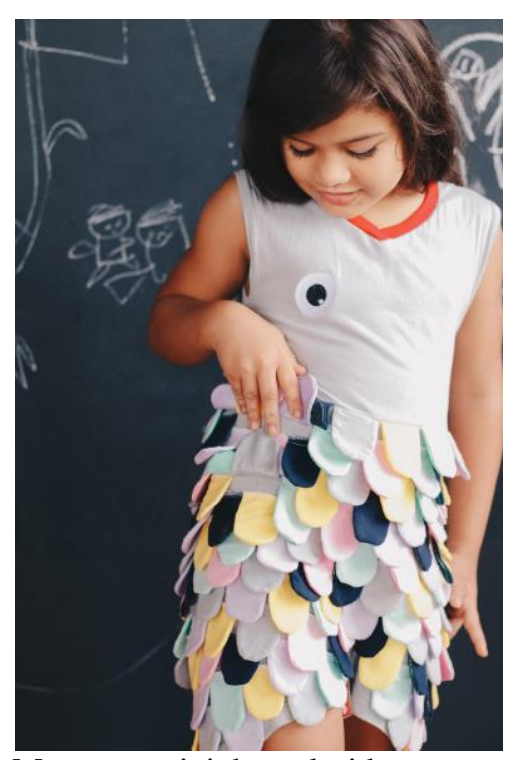

Figura 1: Macacão peixinho colorido Fonte - Própria

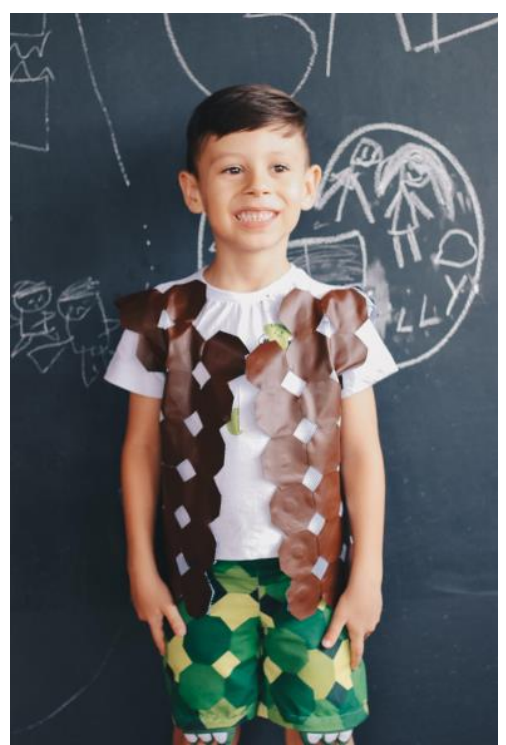

Figura 2: Composição tartaruga ligeirinha Fonte - Própria

Como um complemento à proposta de interatividade dos produtos, outros itens, além do vestuário em si, foram projetados: tag com brincadeiras (figura 3); embalagem em forma de sacola semelhante ao produto do vestuário em questão, contendo um carimbo para que a criança possa brincar (figura 3); boneco com a forma do animal usado como referência na peça, vestido de maneira equivalente (figura 4).

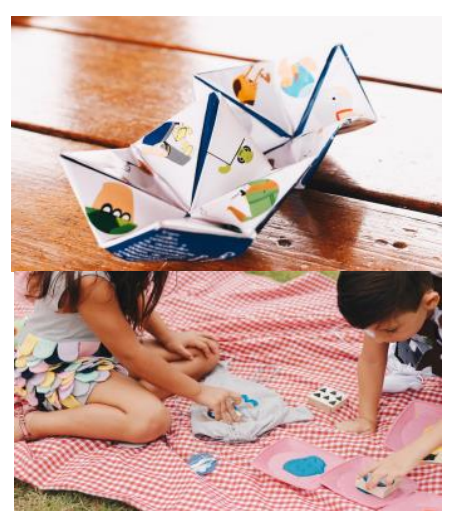

Figura 3: Tag, e Sacola com carimbos Fonte - Própria 

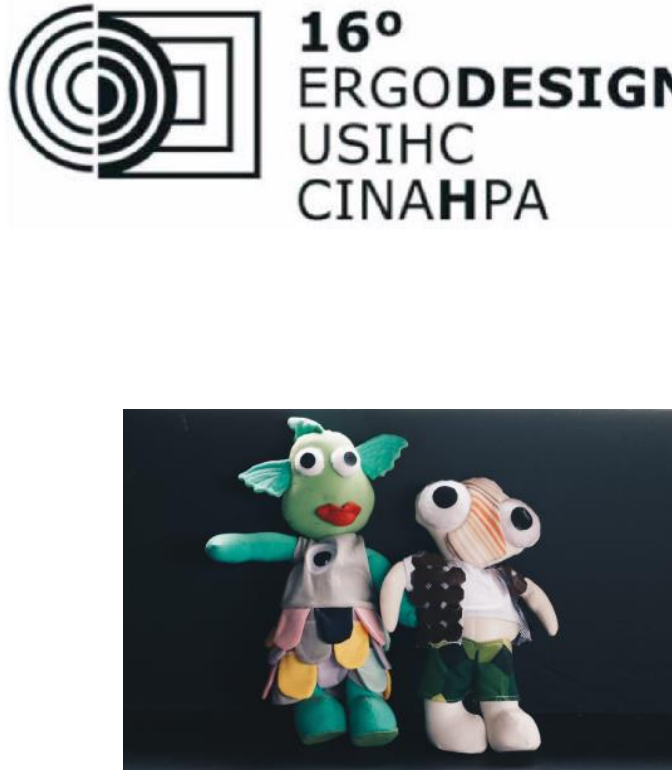

Figura 4: Bonecos

Fonte - Própria

\section{Considerações Finais}

Em face do exposto, é possível inferir que o resultado foi satisfatório. Grande parte dos objetivos elencados foram contemplados, tendo a ergonomia cumprido o papel essencial no alcance destes.

A manipulação das formas, elementos, cores e texturas, bem como os itens adicionais (boneco, bolsa), possibilitaram a interação da criança com a roupa. Ainda, a modelagem com folga positiva viabilizou a mobilidade necessária para o conforto da criança em seus momentos de recreação.

A pesquisa direta com o público-alvo (e seus pais e educadores) possibilitou que os produtos desenvolvidos encontrassem embasamento nas reais necessidades de uso. Um bom exemplo é a adaptação da tabela de medidas a fim de adequá-la ao mesmo.

Naturalmente, o estudo apresenta limitações, principalmente por tratar-se de um projeto desenvolvido em âmbito acadêmico. A dificuldade de acesso a novas matérias primas e tecnologias, bem como o constrangimento dos pais quanto às necessidades educacionais especiais dos filhos foram alguns dos obstáculos encontrados.

Por fim, é importante ressaltar que a prática projetual, considerando públicos não convencionais e geralmente não atendidos, configurou-se como uma excelente oportunidade de compreender melhor o caráter social, especialmente no que diz respeito à inclusão por $16^{\circ}$ Ergodesign - Congresso Internacional de Ergonomia e Usabilidade de Interfaces Humano Tecnológica: Produto, Informações Ambientes Construídos e Transporte

$16^{\circ}$ USIHC - Congresso Internacional de Ergonomia e Usabilidade de Interfaces Humano Computador

CINAHPA | 2017 - Congresso Internacional de Ambientes Hipermídia para Aprendizagem. parte do design. A proposta de se trabalhar sob a perspectiva do design universal objetivava expandir a atuação do design no que concerne ao atendimento das necessidades do ser humano, para além de indivíduos considerados padrão pela sociedade. Compreende-se que o projeto desenvolvido, ainda que não seja de fato universal - no sentido estrito de abarcar toda e qualquer criança, independentemente de suas singularidades -, apresenta avanços significativos se comparado a projetos convencionais não desenvolvidos sob a ótica do design universal em uma perspectiva de inclusão.

\section{Referências Bibliográficas}

\section{ABNT. Segurança de Roupas Infantis:}

Especificações de Cordões fixos e ajustáveis em roupas infantis e aviamentos em geral. Riscos físicos. 2015.

BROUGÈRE, G. Brinquedo e cultura. 6 . ed. São Paulo: Cortez, 2006.

\section{GONÇALVES, L. B. Desenvolvimento}

Cognitivo Infantil: a co-criação como ferramenta auxiliadora. 2017. $129 \mathrm{f}$. Trabalho de Conclusão de Curso (Graduação em Design de Moda), Universidade Estadual de Londrina, Londrina, 2017 - p. 41.

\section{LAWSON, B. Como arquitetos e designers pensam. São Paulo: Oficina de Textos, 2011.}

MARTINS, S. B. Ergonomia e Moda: repensando a segunda pele. BADUY, D. P. Design de Moda: olhares diversos. São Paulo: Estação das Letras e Cores, 2008.

MORACE, F. (org.). Consumo Autoral. As gerações como empresas criativas. São Paulo: Estação das Letras e Cores Editora, 2a ed., 2012.

PEREIRA, L. M. Possibilidade de Aprendizagem no Vestuário Infantil: um estudo exploratório. Bauru, 2011. 131 p. Dissertação (Mestrado em Design) - Universidade Estadual Paulista, 2011. 


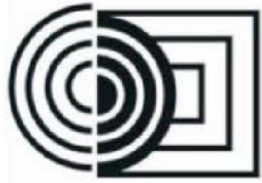

$16^{\circ}$ Ergodesign - Congresso Internacional de Ergonomia e Usabilidade de Interfaces Humano Tecnológica: Produto, Informações Ambientes Construídos e Transporte

$16^{\circ}$ USIHC - Congresso Internacional de Ergonomia e Usabilidade de Interfaces Humano Computador

CINAHPA | 2017 - Congresso Internacional de Ambientes Hipermídia para Aprendizagem.

SANCHES, M. C. F. et. al. Bases para o ensino/aprendizagem de projeto no design de moda: conectando diretrizes didáticas e estratégias metodológicas. Moda Palavra e-Periódico, v. 9, n. 17, p. 119-144, 2016.

SENAI. Apostila de Modelagem de Malha. Curitiba, Jun., 2007.

SEVERINO, A.J. Metodologia do Trabalho Científico. São Paulo: Cortez, 2016.

DESENHO UNIVERSAL. Disponível em: <http://www.mpsp.mp.br/portal/page/portal/Cartilh as/manual-desenho-universal.pdf > Acesso em: 10 mar 2017.

HESS, P.; PACHECO, B. Estudo do corpo de pessoas com síndrome de down para o desenvolvimento de modelagem do vestuário. In: $5^{\circ}$ ENPModa - Encontro Nacional de Pesquisa em Síndrome de Down. Disponível em:

<http://www.feevale.br/Comum/midias/ > Acesso em: 6 dez 2016.

SANCHES, M. C. F. Projeto integrador: uma reflexão para a evolução. Projetica, Londrina, v. 1, n. 1, p. 101-114, dez. 2010. Disponível em: <http://www.uel.br/revistas/uel/index.php/ projetica/article/ view/7707/6859>. Acesso em: 19 jul 2016.

\section{Agradecimentos:}

Aos Professores.

Agradecemos a Deus, nossos familiares e a todos os envolvidos. 